\title{
Library Web Performance Data [dataset]
}

\section{Author: Scott Young}

DOI

http://doi.org/10.15788/m23w2g

Date uploaded

January 2016

\section{Description}

This dataset is associated with the following article: Young, SWH (2016) Speed Matters:

Performance Enhancements for Library Websites. Weave UX 1(4).

http://doi.org/10.3998/weave.12535642.0001.401

\section{Associated Article}

Young, SWH (2016) Speed Matters: Performance Enhancements for Library Websites. Weave UX 1(4). http://doi.org/10.3998/weave.12535642.0001.401

\section{Citations}

Young SWH (2016) Library Web Performance Data [dataset]. Montana State University ScholarWorks. http://doi.org/10.15788/m23w2g 